\title{
Expressed Sequence Tag Analysis for Identification and Characterization of Sex-Related Genes in the Giant Tiger Shrimp Penaeus monodon
}

\author{
Rachanimuk Preechaphol ${ }^{1}$, Rungnapa Leelatanawit ${ }^{1}$, Kanchana Sittikankeaw ${ }^{1}$, Sirawut Klinbunga $^{2,3, *}$, \\ Bavornlak Khamnamtong ${ }^{2,3}$, Narongsak Puanglarp ${ }^{2,3}$ and Piamsak Menasveta ${ }^{2,4}$ \\ ${ }^{1}$ Program in Biotechnology, Faculty of Science, Chulalongkorn University, Bangkok 10330, Thailand \\ ${ }^{2}$ Center of Excellence for Marine Biotechnology, Faculty of Science, Chulalongkorn University, Bangkok 10330, Thailand \\ ${ }^{3}$ Aquatic Molecular Genetics and Biotechnology Laboratory, National Center for Genetic Engineering and Biotechnology (BIOTEC), \\ National Science and Technology Development Agency, 113 Paholyothin Road, Klong 1, Klong Luang, Pathumthani 12120, Thailand \\ ${ }^{4}$ Department of Marine Science, Faculty of Science, Chulalongkorn University, Bangkok 10330, Thailand
}

Received 12 October 2006, Accepted 24 January 2007

Sex-related genes expressed in vitellogenic ovaries of the giant tiger shrimp, Penaeus monodon, were identified by an EST approach. A total of 1051 clones were unidirectionally sequenced from the 5 terminus. Nucleotide sequences of 743 EST $(70.7 \%)$ significantly matched known genes previously deposited in the GenBank (E-value $<\mathbf{1 0}^{-4}$ ) whereas 308 ESTs $(29.3 \%)$ were regarded as newly unidentified transcripts (E-value $>10^{-4}$ ). A total of 559 transcripts (87 contigs and 472 singletons) were obtained. Thrombospondin (TSP) and peritrophin (79 and 87 clones accounting for 7.5 and $8.3 \%$ of clones sequenced, respectively) predominated among characterized transcripts. Several full length transcripts (e.g. cyclophilin, profillin and thioredoxin peroxidase) were also isolated. A gene homologue encoding chromobox protein (PMCBX, ORF of 567 nucleotides encoding a protein of 188 amino acids) which is recognized as a new member of the $H P 1$ family was identified. Expression patterns of 14 of 25 sex-related gene homologues in ovaries and testes of $P$. monodon broodstock were examined by RT-PCR. Female sterile and ovarian lipoprotein receptor homologues were only expressed in ovaries whereas the remaining transcripts except disulfide isomerase related $P 5$ precursor and adenine nucleotide translocator 2 were higher expressed in ovaries than testes of $P$. monodon broodstock. A homologue of ubiquitin specific proteinase 9, X chromosome (Usp9X) revealed a preferential expression level in ovaries than testes of broodstock-sized $P$. monodon $(N=13$ and $11, P$ $<0.05$ ) but was only expressed in ovaries of 4-month-old $\operatorname{shrimp}(N=5$ for each sex $)$.

\footnotetext{
*To whom correspondence should be addressed.

Tel: 66-2-2185279; Fax: 66-2-2547680

E-mail: sirawut@biotec.or.th
}

Keywords: EST, Penaeus monodon, RT-PCR, Sex-specific markers, Shrimp

\section{Introduction}

The giant tiger shrimp, Penaeus monodon, is one of economically important cultured species (Rosenberry, 2003). Annual production of farmed $P$. monodon in Thailand alone had greater than 200,000 metric tons since 1993 (Asian Shrimp Culture Council, 1996). Farming of P. monodon in Thailand relies almost entirely on wild-caught broodstock for supply of juveniles because reproductive maturation of cultured $P$. monodon female is extremely low. As a result, breeding of pond-reared $P$. monodon is extremely difficult and rarely produced enough quality of larvae required by the industry. The high demand on wild female broodstock leads to overexploitation of the natural populations of $P$. monodon in Thai waters (Klinbunga et al., 1999). The price of a gravid wild female of $P$. monodon from the Andaman Sea (west of peninsular Thailand) is approximately $\$ 200$ USD which is 3-5 times greater than for that from the Gulf of Thailand (east). This situation resulted from farmer demand since farmers believe that progeny of Andaman Sea $P$. monodon exhibit greater growth and possibly survival rates than do progeny from broodstock shrimp caught elsewhere in Thailand (Klinbunga et al., 1999 and 2001).

Besides problems from diseases, the lack of high quality wild and/or domesticated broodstock of $P$. monodon has possibly caused an occurrence of a large portion of stunted shrimp at the harvest time (less than $10 \mathrm{~g}$ rather than approximately $25 \mathrm{~g}$ body weight at 4 month cultivation period). The farmed production of $P$. monodon has significantly 
decreased since the last few years. As a result, domesticated Pacific white shrimp, Litopenaeus vannamei, has recently been introduced to Thailand as a new cultured species (Khamnamtong et al., 2005) and initially contributed approximately $20000 \mathrm{MT}(7.4 \%)$ of the cultured production in 2002 and dramatically increased to 220000 MT (73.3\%) in 2004, respectively (Limsuwan, 2004).

The domestication and selective breeding programs of penaeid shrimp would provide a more reliable supply of seed stock and the improvement of their production efficiency (Makinouchi and Hirata, 1995; Clifford and Preston, 2006; Coman et al., 2006). The use of selectively bred stocks having improved culture performance, disease resistance and/or other commercially desired traits rather than the reliance on wildcaught stocks is a major determinant of sustainability of the shrimp industry (Clifford and Preston, 2006). Despite the potential benefits, the domestication of $P$. monodon has been remarkably slow in Thailand (Withyachumnarnkul et al., 1998) and is still at the initial stage.

In P. monodon, females exhibit approximately $10-20 \%$ greater growth rate than do males (Browdy, 1998). The diploid chromosome numbers of penaeid shrimp are $2 N=88$ 92 where $P$. monodon possesses $2 N=88$ (Benzie, 1998). Neither sex chromosomes nor environmental sex determination has been reported in penaeid shrimp.

Eyestalk ablation is used commercially to induce ovarian maturation of penaeid shrimp but the technique leads to an eventual loss in egg quality and death of the spawner (Benzie, 1998). Therefore, predictable maturation and spawning of captive penaeid shrimp without the use of eyestalk ablation is a long-term goal for the industry (Quackenbush, 2001).

Apart from the control of reproductive maturation, manipulation of sex ratio is an important tool for crustacean aquaculture (Lyons and Li, 2002). An understanding of sex determination and differentiation is, therefore, necessary for designing appropriate breeding programs in penaeid species. Li et al. (2003) constructed genetic linkage maps of the kuruma shrimp, Marsupenaeus japonicus, based on AFLP analysis and revealed that sex of female progeny $(N=54)$ was tightly mapped to the linkage group 28 of the female map $(\mathrm{LOD}=5.0)$ which led to the argument of female heterogamy (ZW) in this species. Moreover, triploidy affects the sex ratio in Fenneropenaeus chinensis (Li et al., 2003) and $M$. japonicus (Preston et al., 2004) where the female-to-male ratio was almost $4: 1$ in the former but all triploids were female in the latter. These further support complex heterogametic sex in penaeid shrimp (Preston et al., 2004).

The development of oocytes consists of a series of complex cellular events, in which different genes express to ensure the proper development of oocytes and to store transcripts and proteins as maternal factors for early embryogenesis (Qiu and Yamano, 2005). Different biotechnological approaches, for example; injection of vertebrate steroid hormones, neurotransmitters and ecdysteroids (Benzie 1998; Okumura, 2004) and the use of specially formulated feed (Harrison, 1990) have been applied to induce the ovarian maturation of female shrimp but results are inconsistent owing to limited knowledge on genetic and hormonal control of penaeid species (Meusy and Payen, 1988; Okumura, 2004). Accordingly, an initial step toward understanding molecular mechanisms of ovarian (and oocyte) maturation and sex differentiation cascades in $P$. monodon is the identification and characterization of sexrelated genes expressed in ovaries of this economically important species.

Recently, an EST approach (single-pass sequencing of randomly selected clones from cDNA libraries) has been successfully applied and recognized as an effective method for discovery of immune related genes in L. vannamei and $L$. setiferus (Gross et al., 2001), M. japonicus (Rojtinnakorn et al., 2002), F. chinenesis (Shen et al., 2004) and P. monodon (Supungul et al., 2004). In the present study, an ovarian cDNA library was constructed and 1051 randomly selected clones were sequenced to identify sex-related transcripts in $P$. monodon. The expression profiles of interesting ESTs in ovaries and testes of $P$. monodon were further examined using reverse transcription-polymerase chain reaction (RT-PCR). Transcripts only expressed in ovaries but not testes (and those expressed higher in ovaries than testes) of $P$. monodon are reported.

\section{Materials and Methods}

Experimental animals and RNA isolation. Female broodstock of P. monodon used for construction of a cDNA library was collected from Satun (west of peninsular Thailand). In addition, juvenile (4month-old) and broodstock-sized shrimp used for RT-PCR analysis were purchased from a commercial farm in Chachoengsao (eastern Thailand) and wild-caught from Chonburi (Gulf of Thailand, east), respectively. Total RNA was extracted from ovaries or testes of each shrimp using TRI-REAGENT (Molecular Research Center). Messenger ( $m$ ) RNA was further purified using a QuickPrep Micro mRNA Purification Kit (GE Healthcare) and kept under the absolute ethanol at $-70^{\circ} \mathrm{C}$ prior to reverse transcription.

Construction of a normal cDNA library and EST analysis. Five microgram of mRNA from vitellogenic ovaries of wild $P$. monodon was reversed transcribed and second-stranded synthesized using a ZAP-cDNA Synthesis and Cloning Kit (BD Biosciences Clontech). Size-selected cDNAs ( $>500 \mathrm{bp}$ ) were cloned into dephosphorylated EcoRI/Xho I-digested Uni-ZAP ${ }^{\circledR} \mathrm{XR}$ and transfected into E. coli XL1-Blue MRF'. The lambda library was converted into the pBluescript library by in vivo excision. Recombinant clones were selected by a lac $Z$ system following standard protocols (Sambrook and Russell, 2001). Recombinant clones were randomly selected from those carrying insert sizes greater than 500 bp (Srisuparbh et al., 2003). Plasmid DNA was extracted and unidirectionally sequenced on a MegaBase 1000 automated DNA sequencer (GE Healthcare).

EST clustering and assembly. Nucleotide sequences of ESTs were compared with those previously deposited in the GenBank using 
BLASTN and BLASTX (Altschul et al., 1990, available at http:// www.ncbi.nlm.nih.gov). Significant matched nucleotides/proteins were considered when the E-value was $<10^{-4}$. Clustering and assembling of sequences were performed using TIGR Gene Indices Clustering Tools (TGICL) (Pertea et al., 2003) with CAP3 (Huang and Madan, 1999).

Phylogenetic analysis of a chromobox (CBX) gene homologue. Protein sequences of different isoforms of $C B X$ from various species; Apis mellifera (AMZGC, XM_393875), Homo sapiens (HSHP1 $\gamma$, U26312; HSCBX3, NM_007276; HSHP1, AF13660; HSCBX5-HP1 $\alpha$, CR457418; HSCBX5, NM 012117 and HSCBX1, NM_006807), Mus musculus (MMCBX3, NM_007624 and $M M C B X 5$, NM_007626), Gallus gallus (GGCBX3, NM_204643 and GGCBX1, NM_204332), Xenopus laevis (XLHP1 $\gamma$, AY168926; $X L C B X 3, \mathrm{BC} 046570$ and XLHP1 $\alpha$, AF009820), Cricetulus griseus (CGHP1 $\alpha, \mathrm{AY} 548740$ and CGHP1 $\beta$, AY548739), Danio rerio (DRCBX1, NM_199746), were retrieved from the GenBank and compared with that of $P$. monodon. Multiple alignments were carried out using ClustalW (Thompson et al., 1994). Sequences were bootstrapped 1000 times using Seqboot. The divergence between pairs of protein sequences was estimated using Prodist. A bootstrapped neighbor-joining tree (Saitou and Nei, 1987) was constructed to illustrate phylogenetic relationships among sequences using Neighbor and Consense. All phylogenetic programs described were routine in PHYLIP (Felsenstein, 1993).

RT-PCR of sex-related gene homologues. One microgram of total RNA extracted from ovaries or testes of juvenile and broodstock $P$. monodon was reverse-transcribed and $100 \mathrm{ng}$ of the first strand cDNA was used as the template for amplification of sex-related gene homologues in a $25 \mu \mathrm{l}$ reaction volume containing $10 \mathrm{mM}$ Tris-HCl, pH 8.8, $50 \mathrm{mM} \mathrm{KCl}, 0.1 \%$ Triton X-100, $1.5 \mathrm{mM}$ of $\mathrm{MgCl}_{2}, 0.2 \mathrm{mM}$ of each dNTP, $0.2 \mu \mathrm{M}$ of each primer and $1 \mathrm{U}$ of Dynazyme $^{\mathrm{TM}}$ II DNA polymerase. Elongation factor-1 $\alpha(E F-1 \alpha)$ or $\beta$-actin was included as a positive control. RT-PCR was initially performed by predenaturation at $94^{\circ} \mathrm{C}$ for $3 \mathrm{~min}$ followed by 25 (semi-quantitative RT-PCR for transcripts that show differential expression between ovaries and testes) or 30 (end-point RT-PCR for transcripts that were only expressed in ovaries but not testes) cycles of a $94^{\circ} \mathrm{C}$ denaturation for $30 \mathrm{~s}$, a $53^{\circ} \mathrm{C}$ annealing for $60 \mathrm{~s}$ and a $72^{\circ} \mathrm{C}$ extension for $30 \mathrm{~s}$. The final extension was carried out at $72^{\circ} \mathrm{C}$ for $7 \mathrm{~min}$. Amplicons were electrophoretically analyzed through $1.5 \%$ agarose gels and visualized with a UV transilluminator after ethidium bromide staining (Sambrook and Russell, 2001). The intensity of interesting genes and that of $E F-1 \alpha$ or $\beta$-actin was quantified from the scanned photograph of the gel using the Quantity One software (BioRad). Relative expression levels of investigated transcripts (intensity of target/intensity of $E F-1 \alpha$ or $\beta$ actin) in ovaries and testes of $P$. monodon were statistically tested using one way analysis of variance (ANOVA).

\section{Results and Discussion}

An ovarian cDNA library was established for isolation of genes involving ovarian (and oocyte) development in $P$.

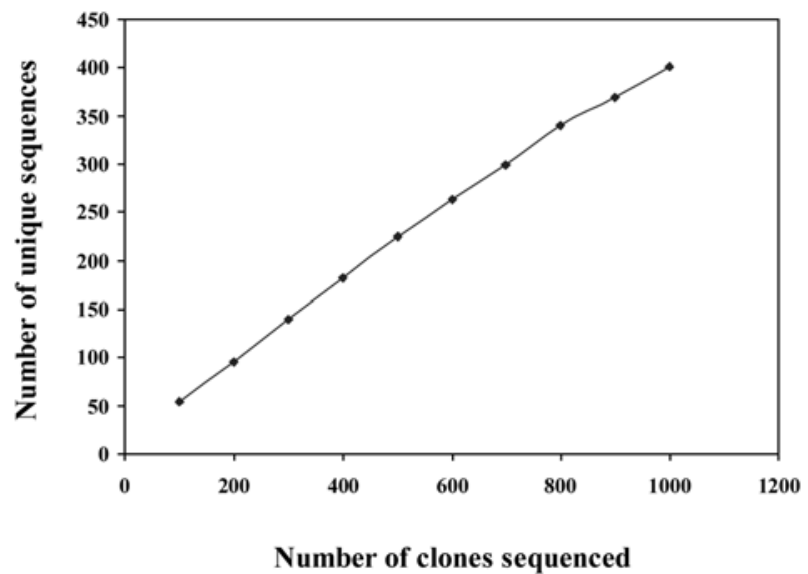

Fig. 1. Number of unique sequences plotted as a function of the accumulative number of clones sequenced from the ovarian cDNA library of $P$. monodon.

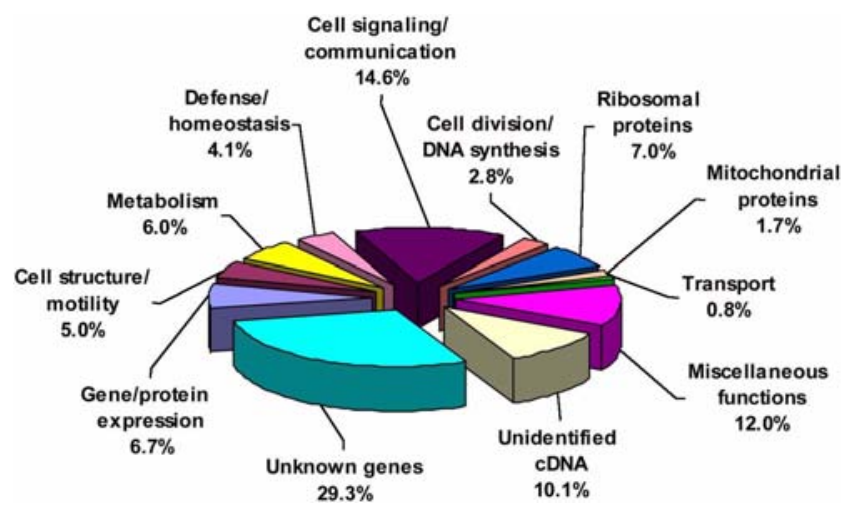

Fig. 2. Classification of genes identified in the ovarian cDNA libraries of $P$. monodon (E-value $<10^{-4}$ ) owing to functional categories of their homologues.

monodon. The primary titer of a cDNA library was approximately $4 \times 10^{6} \mathrm{pfu} / \mathrm{ml}$. From 1051 recombinant clones sequenced, a total of 743 ESTs $(70.7 \%)$ corresponded to known sequences in the GenBank $\left(\right.$ E-value $\left.<10^{-4}\right)$ whereas the remaining sequences were regarded as novel (unknown) transcripts $\left(29.3 \%\right.$, E-value $\left.>10^{-4}\right)$. The percentage of unknown transcripts found in the present study was lower than that previously reported in hemocyte cDNA libraries of normal $(44.7 \%)$ and WSSV-infected $(47.0 \%) \quad M$. japonicus (Rojtinnakorn et al., 2002) but greater than the percentage of unknown transcript (E-value $>10^{-2}$ ) in hemocyte and hepatopancreas cDNA libraries of $L$. vannamei (15.7\%, Gross et al., 2001) and L. setiferus (29.5\%, Gross et al., 2001).

The relationship between the number of clones sequenced and the accumulative numbers of unique transcripts indicated that the discovery rate of new transcripts still does not reach a plateau of saturation and is greater than $10 \%$ after 1051 recombinant clones were sequenced (Fig. 1). Therefore, additional unique transcripts can still be identified by sequencing a larger number of recombinant clones. Five 


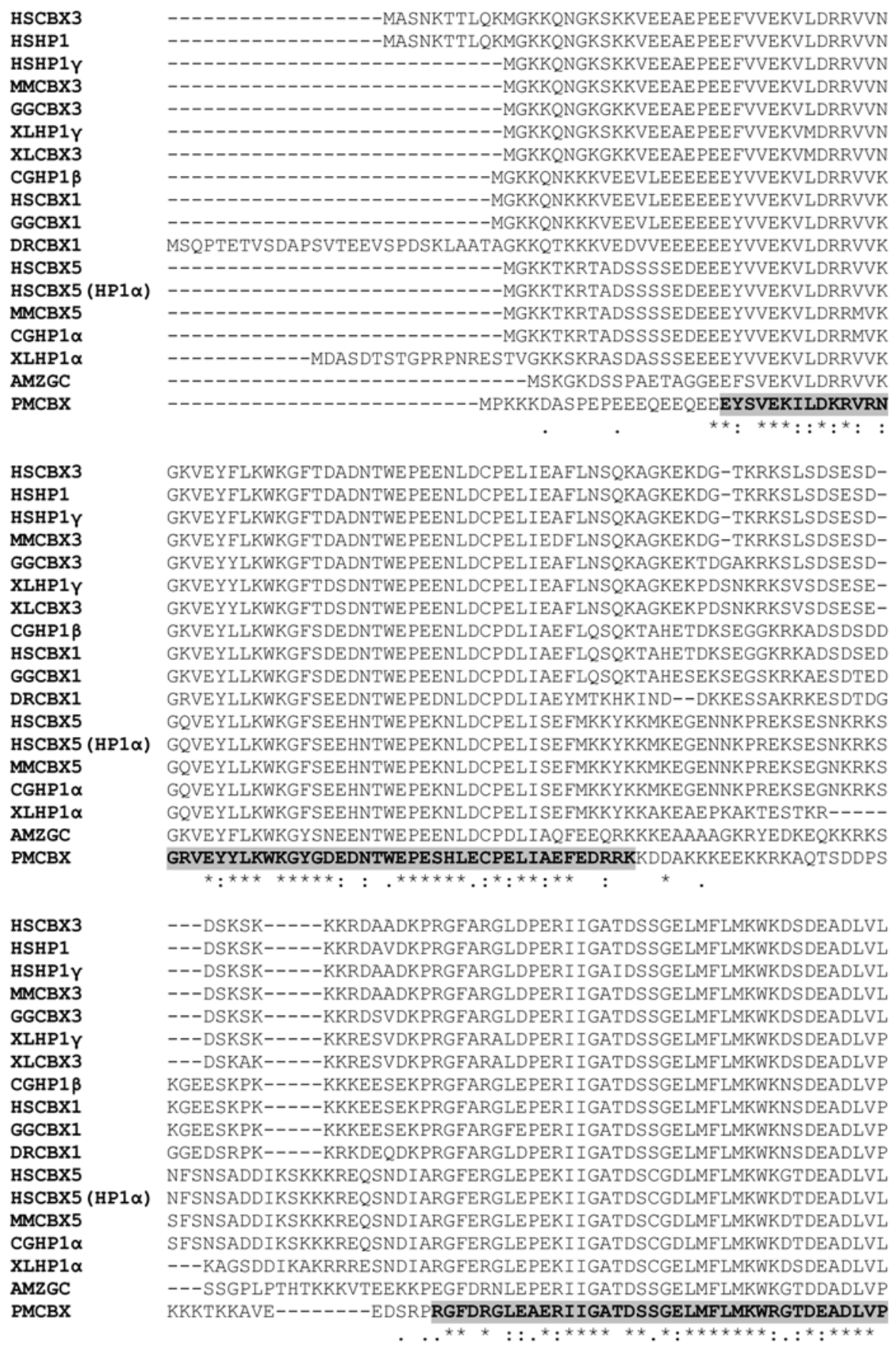

Fig. 3. Multiple alignments of $C B X$ from various species and a $C B X$ homologue of $P$. monodon (PMCBX). CHROMO (positions 21-73, $\mathrm{E}$-value $=1.6 \mathrm{e}-29)$ and $\mathrm{ChSh}$ (positions 109-171, E-value $=2.0 \mathrm{e}-20$ ) domains in $P M C B X$ are boldfaced and highlighted.

hundred and fifty-nine transcripts (87 contigs and 472 singletons) were obtained after clustering analysis. The relatively high rate of gene discovery and a large number of transcripts obtained indicated that the established library is reasonably diverse.

Among known transcripts in the ovarian cDNA library of $P$. monodon, ESTs categorized as members of signaling and communication were predominant (14.6\%) followed by those classified as members of miscellaneous function $(12.0 \%)$, unidentified function $(10.1 \%)$, gene expression and protein synthesis $(6.7 \%)$, metabolism $(6.0 \%)$ and internal/external structure $(5.0 \%)$ groups. The remaining ESTs allocated to other functional categories were accounted for less than $5.0 \%$ of the characterized ESTs in this library (Fig. 2).

In a recent study by Leelatanawit et al. (2004), a total of 218 clones from subtraction suppressive hybridization (SSH) cDNA libraries between ovaries and testes of $P$. monodon broodstock were unidirectionally sequenced. Most of the 


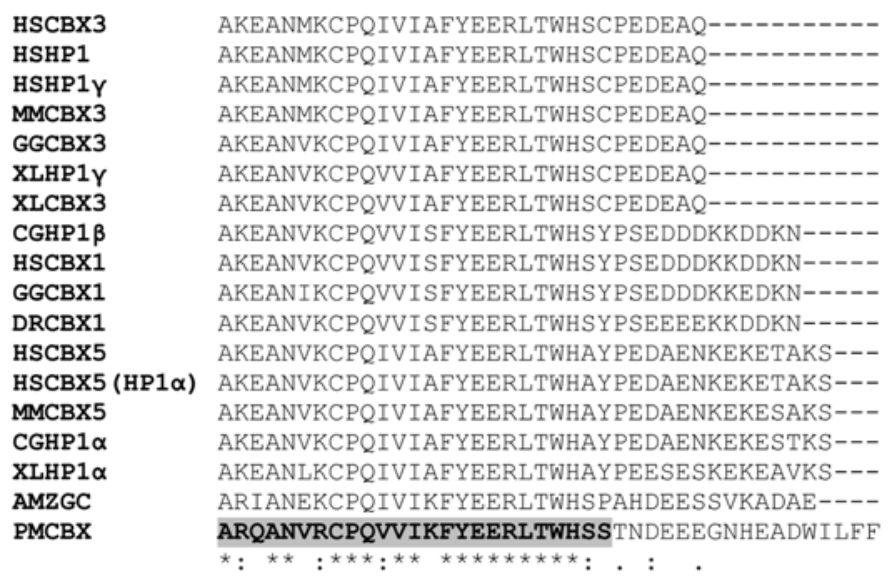

Fig. 3. Continued.

expressed genes in ovaries encoded thrombospondin (TSP, 45 clones accounting for $28.7 \%$ of total investigated ESTs), peritrophin (17 clones, 10.8\%), and unknown transcripts (78 clones, 49.7\%). Conversely, almost all of the ESTs in $P$. monodon testes were unknown transcripts (59 clones, 96.7\%).

In this study, homologues of TSP (79 clones, $7.5 \%$ of sequenced clones) and peritrophin (87 clones, 8.3\%) were abundantly expressed in vitellogenic ovaries of $P$. monodon but surprisingly lower than those in previously reported $\mathrm{SSH}$ libraries (Leelatanawit et al., 2004). Recently, complete sequences of three closely related TSP homologues encoding the major cortical rod proteins of 1114, 1032, and 991 amino acids (GenBank accession numbers AB121209, AB121210, and $\mathrm{AB} 121211)$ were isolated and characterized in $M$. japonicus (Yamano et al., 2004). MjTSP protein levels dramatically increased after eyestalk ablation (Okumura et al., 2006). In $P$. monodon, expression of TSP were specifically found in ovaries $(N=20)$ but not in testes $(N=22)$ of broodstock-sized $P$. monodon (Leelatanawit et al., 2004). In the present study, preferential expression of TSP in ovaries than testes of 4-month-old P. monodon was found ( $p<0.05)$.

Peritrophin, a major component of cortical rods and is the precursor of the jelly layer of the shrimp eggs, is highly expressed during oocyte development of marine shrimp (Khayat et al., 2001). Synthesis of peritrophin in ovaries of $P$. semisulcatus is inhibited by crustacean hyperglycemic hormone $(\mathrm{CHH})$ purified from the sinus gland extract of $M$. japonicus (Avarre et al., 2001). Peritrophin was not differentially expressed between ovaries and testes of $P$. monodon broodstock (Leelatanawit et al., 2004) and between different stages of ovarian development of M. japonicus after eyestalk ablation (Okumura et al., 2006). The recombinant peritrophin-like protein of $F$. merguiensis has the activity of binding Gram-negative bacteria and strong binding activity to chitin suggesting that it may also play an important role in the immune defense mechanisms (Du et al., 2006).

Several full length transcripts of functionally important genes including chromobox protein (CBX; ORF of $567 \mathrm{bp}$, encoding a polypeptide of 188 aa; Fig. 3), cyclophilin 1 (519

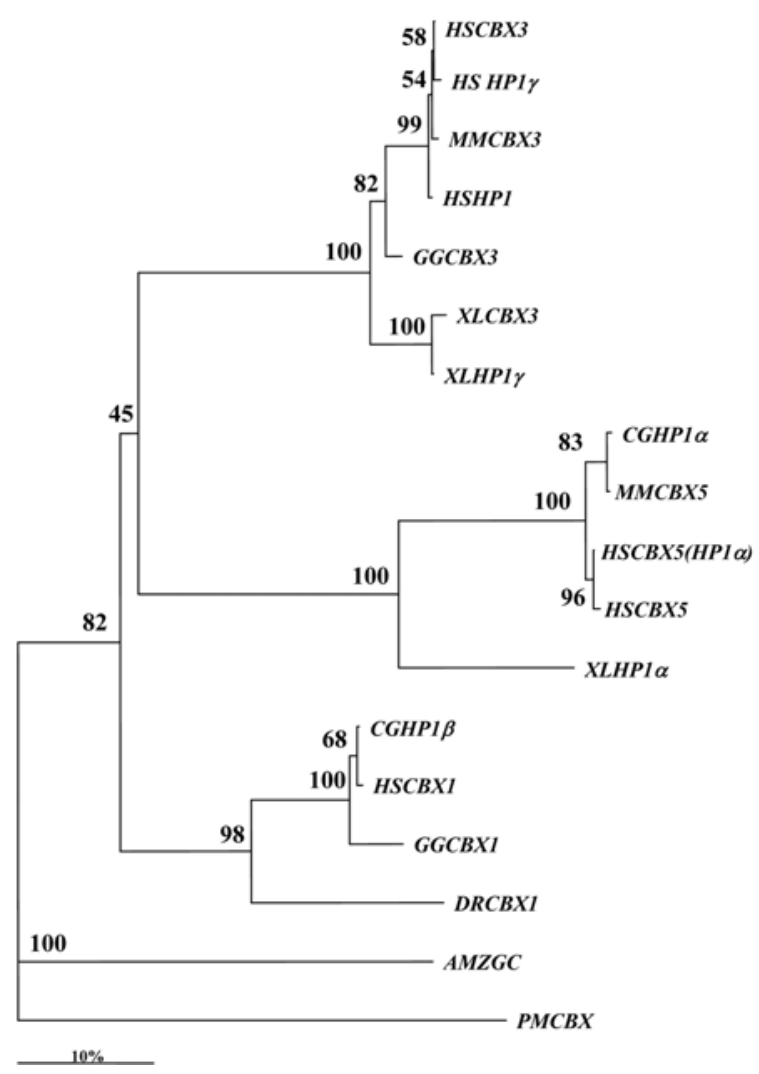

Fig. 4. A bootstrapped neighbor-joining tree illustrating relationships between a homologue of $C B X$ from $P$. monodon $(P M C B X)$, and that of various taxa. Values at the node represent the percentage of times that the particular node occurred in 1000 trees generated by bootstrapping the original aligned protein sequences. A scale bar indicates $10 \%$ of protein sequence divergence.

bp, 172 aa), cytochrome c oxidase subunit Va (462 bp, 153 aa), eIF-5A (474 bp, 157 aa), histone 1 (411 bp, 136 aa), histone $H 2 A$ variant (399 bp, $132 \mathrm{aa}$ ), profillin (381 bp, 126 aa), signal peptidase complex; sid2895p (540 bp, 179 aa), stress-associated endoplasmic reticulum protein 1 (201 bp, 66 
Table 1. A summary of homologues of sex-linked or sex differentiation-related transcripts found in the ovarian cDNA library of $P$. monodon

\begin{tabular}{|c|c|c|c|c|}
\hline Transcripts* & Matched species & Size (bp) & E-value & Linked** \\
\hline$C G 9946-P A$ & Drosophila melanogaster & 738 & $3 e-65$ & $\mathrm{X}$ \\
\hline Brain mitochondrial carrier protein 1 & Homo sapiens & 671 & $3 e-43$ & $\mathrm{X}$ \\
\hline Thioredoxin peroxidase & Homo sapiens & 923 & $7 e-68$ & $\mathrm{X}$ \\
\hline NADPH-cytochrome P450 reductase & Anopheles gambiae & 698 & $8 e-26$ & $\mathrm{X}$ \\
\hline Phosphatidylinositol 4 kinase & Caenorhabditis elegans & 725 & $3 e-13$ & $\mathrm{X}$ \\
\hline ENSANGP00000019081 & Anopheles gambiae & 452 & $6 e-22$ & $\mathrm{X}$ \\
\hline Rab-protein 10 CG17060-PA & Drosophila melanogaster & 892 & $1 \mathrm{e}-88$ & $\mathrm{X}$ \\
\hline Ubiquitin specific protease 9 & Mus musculus & 891 & $5 e-58$ & $\mathrm{X}$ \\
\hline ENSANGP00000011950 & Anopheles gambiae & 866 & $2 e-87$ & $\mathrm{X}$ \\
\hline Female sterile (1) M3 & Drosophila melanogaster & 884 & $2 e-07$ & $\mathrm{X}$ \\
\hline Protein disulfide isomerase-related P5 precursor & Caenorhabditis elegans & 651 & $3 e-61$ & $\mathrm{X}$ \\
\hline ENSANGP00000022750 & Anopheles gambiae & 666 & $2 e-89$ & $\mathrm{X}$ \\
\hline Ribosomal protein $L 1$, isoform $D$ & Drosophila melanogaster & 611 & $7 e-62$ & $\mathrm{X}$ \\
\hline $\begin{array}{l}\text { NADP-dependent leukotriene B4 12-hydroxy- } \\
\text { dehydrogenase (15-oxoprostaglandin 13-reductase) }\end{array}$ & Tribolium castaneum & 923 & $6 e-37$ & Not known \\
\hline Nuclear autoantigenic sperm protein & Homo sapiens & 639 & $5 e-25$ & 1 \\
\hline $\begin{array}{l}X \text {-linked eukaryotic translation initiation factor } \\
\text { isoform } 3\end{array}$ & Tribolium castaneum & 797 & $4 \mathrm{e}-93$ & $\mathrm{X}$ \\
\hline$C G 1681-P A$ & Drosophila melanogaster & 452 & $2 \mathrm{e}-09$ & $\mathrm{X}$ \\
\hline Adenine nucleotide translocator 2 & Homo sapiens & 554 & $1 \mathrm{e}-93$ & $\mathrm{X}$ \\
\hline Chromobox protein & Gallus gallus & 745 & $2 e-46$ & $\mathrm{~W}$ \\
\hline Small androgen receptor-interacting protein isoform 1 & Canis familiaris & 578 & $3 e-30$ & 1 \\
\hline Vitellogenin & Fenneropenaeus merguiensis & 801 & $6 e-97$ & Not known \\
\hline Ovarian lipoprotein receptor & Penaeus semisulcatus & 923 & $4 e-94$ & Not known \\
\hline Y-box protein $C t-p 0$ & Chironomus tentans & 846 & $3 e-10$ & Not known \\
\hline Polehole & Drosophila melanogaster & 725 & $4 e-09$ & 1 \\
\hline Zonadhesin precursor & Homo sapiens & 653 & $1 e-10$ & 7 \\
\hline
\end{tabular}

*GenBank accession number EE332433-EE332457. **Localization in chromosomes of matched species

aa) and thioredoxin peroxidase (591 bp, $196 \mathrm{aa}$ ), homologues were also discovered (GenBank accession numbers EE332458EE332467).

The chromobox protein $(C B X)$ is composing of $C B X 5$ (or heterochromatic $1 \alpha, H P 1 \alpha), C B X 1(H P 1 \beta)$ and $C B X 3(H P 1 \gamma)$ which is an evolutionarily conserved family of proteins involved in the packaging of chromosomal domains into representative heterochromatic states (Jones et al., 2001) and W-linked in chicken (Yamaguchi et al., 1998). In the present study, a homologue of $C B X(\mathrm{ORF}=567 \mathrm{bp}, 188$ aa) was identified in $P$. monodon. The chromatin organization modifier (CHROMO, positions 21-73; Fig. 3) domain and the chromo shadow domain (ChSh, positions 109-171; Fig. 3) were found in this putative non-secretory protein. Phylogenetic analysis suggested that $C B X 5(H P 1 \alpha), C B X 1(H P 1 \beta)$ and $C B X 3$ $(H P 1 \gamma)$ in vertebrates were born from the gene duplication process (Fig. 4) and $P M C B X$ is regarded as a new member of invertebrate $C B X$-related proteins.

Recent advances in the genetic mapping of M. japonicus (Li et al., 2003) and sex ratio alteration in F. chinensis (Li et al., 2003) and M. japonicus (Preston et al., 2004) implied possible female heterogamy (ZW) in penaeid shrimp. Accordingly, identification and characterization of SNP in sex-related (W-linked for $C B X$ and X-linked for others; Table 1) gene homologues of the originally matched species of $P$. monodon ESTs may provide the possibility to further develop genomic sex determination markers for which no DNA markers are available in any penaeid species at present.

In addition, homologues of 25 different sex-related genes were also found from EST analysis (Table 1) and 10 of which were homologous to genes of Drosophila and Anopheles. Homologues of female sterile and ovarian lipoprotein receptor were specifically expressed in ovaries but not testes of $P$. monodon broodstock $(N=5$ for each sex, Table 2 and Fig. 5). Both female sterile and its related protein, polehole are required for the activation of the Tor receptor which are important for eggshell integrity and embryonic development (Perrimon et al., 1986).

The fundamental controls of growth in penaeid shrimp are largely unstudied. Several genes encoding vertebrate-like growth factors and cell cycle regulating proteins (cyclin, cyclin dependent kinase, cell division cycle 2 and epithelial 
Table 2. Primer sequence and expression patterns of sex-related transcripts and the positive control (elongation factor-1 $\alpha$ and $\beta$-actin) of $P$. monodon

\begin{tabular}{|c|c|c|c|}
\hline Transcripts & Primer sequence & $\begin{array}{l}\text { Expected } \\
\text { size }\end{array}$ & $\begin{array}{c}\text { Expression } \\
\text { pattern* }\end{array}$ \\
\hline \multirow[t]{2}{*}{ Thioredoxin peroxidase } & F: 5'-CGAAGTGGTTGCTTGCTCTA-3' & 233 & $\mathrm{HO}$ \\
\hline & R: 5'-CTGGCAGGTCATTGATTGTT-3' & & \\
\hline \multirow[t]{2}{*}{ Phosphatidylinositol 4 kinase } & F: 5'-CAACGCCATCAACTCCATCAC-3' & 335 & $\mathrm{HO}$ \\
\hline & R: 5'-CTTCCAGCACCACACAGTTTTAT-3' & & \\
\hline \multirow[t]{2}{*}{ Rab-protein 10 CG17060-PA } & F: 5'-CTATTACAGAGGGGCAATGGGC-3' & 177 & $\mathrm{HO}$ \\
\hline & R: 5'-TTTTCTTTGGCAATGACACGCT-3' & & \\
\hline \multirow[t]{2}{*}{ Ubiquitin specific protease 9} & F: 5'-GGAAATGGACCTGGGCGG-3' & 247 & $\mathrm{HO}$ \\
\hline & R: 5'-TCTTCTGGAACTGCTACCTCTGC-3' & & \\
\hline \multirow[t]{2}{*}{ Female sterile } & F: 5'-GCAATAACGGTGAACAAGGGA-3' & 296 & $\mathrm{O}$ \\
\hline & R: 5'-GCAACCACATTAGTAGCCATA-3' & & \\
\hline \multirow[t]{2}{*}{ Protein disulfide isomerase-related P5 precursor } & F: 5'-GCCGTTGCCAATAAGGACGA-3' & 180 & OT \\
\hline & R: 5'-TCACCCGCCTTGAGATTGGT-3' & & \\
\hline \multirow[t]{2}{*}{$\operatorname{agCP} 13148$} & F: 5'-CATACCTCGCATCATCAGTG-3' & 212 & $\mathrm{HO}$ \\
\hline & R: 5'-CCTCAGGAGACGATACAAAGC-3' & & \\
\hline \multirow[t]{2}{*}{ Nuclear autoantigenic sperm protein } & F: 5'-AGGAAATGGAAACTGATGTCGC-3' & 301 & $\mathrm{O}$ \\
\hline & R: 5'-TTCTTAGCCATCTCTGGGTTGT-3' & & \\
\hline \multirow{2}{*}{ Adenine nucleotide translocator 2} & F: 5'-GTCCGCATCCCAAAGGAACGAG-3' & 239 & OT \\
\hline & R: 5'-CGAGCGAAGTCAAGGGGGTAGA-3' & & \\
\hline \multirow[t]{2}{*}{ Chromobox protein } & F: 5'-TGGGAACCTGAATCTCATCTTG-3' & 303 & $\mathrm{HO}$ \\
\hline & R: 5'-ACGAACATTTGCCTGCCTTG-3' & & \\
\hline \multirow[t]{2}{*}{ Small androgen receptor interacting protein } & F: 5'-GGCTTAGTGACTGAACGCCTCTA-3' & 155 & $\mathrm{HO}$ \\
\hline & R: 5'-GCTGCTCTACTACGCACAACAC-3' & & \\
\hline \multirow[t]{2}{*}{ Ovarian lipoprotein receptor } & F: 5'-CGGGATGAGTGCGAGAAGTGC-3' & 354 & $\mathrm{O}$ \\
\hline & R: 5'-CAGGGGCTCCGAGTCAAAGA-3' & & \\
\hline \multirow[t]{2}{*}{ Y-box protein $C t-p 0$} & F: 5'-CGGAGACACAAGCCAAGCCT-3' & 435 & $\mathrm{HO}$ \\
\hline & R: 5'-GGTGGAACCCAACCAGCAAC-3' & & \\
\hline \multirow[t]{2}{*}{ Zonadhesin precursor } & F: 5'-CCTGGGCGTAGCTAATCTTAAC-3' & 177 & $\mathrm{HO}$ \\
\hline & R: 5'-TCGGTAGGGCCATATCCTCTCC-3' & & \\
\hline \multirow[t]{2}{*}{ elongation factor-1 $\alpha$} & F: 5'-ATGGTTGTCAACTTTGCCCC-3' & 500 & Control \\
\hline & R: 5'-TTGACCTCCTTGATCACACC-3' & & \\
\hline \multirow[t]{2}{*}{$\beta$-actin } & F: 5'-GGTATCCTCACCCTCAAGTA-3' & 327 & Control \\
\hline & R: 5'-AAGAGCGAAACCTTCATAGA-3' & & \\
\hline
\end{tabular}

* $\mathrm{HO}=$ higher expression in ovaries than testes $(P<0.05)$, OT $=$ expression levels in ovaries and testes were not different $(P>0.05)$, $\mathrm{O}=$ specific expression in ovaries of broodstock-sized $P$. monodon.

growth factor 1) were identified. Additionally, nuclear autoantigenic sperm protein (NASP) which was first described in rabbit and designated a homologue to the Xenopus oocyte histone binding protein N1/N2 (Welch and O'Rand 1990) were also discovered. $N A S P$ is found in all dividing cells as either a somatic/embryonic $(s N A S P)$ or a testis/embryonic ( $t N A S P$ ) isoforms (Richardson et al., 2000). Overexpression of $t N A S P$ affects progression through the cell cycle. In mice, HSP90 acts as a $t N A S P$-binding partner (Alekseev et al., 2005). This transcript showed significant higher expression in ovaries than testes of broodstock-sized $P$. monodon ( $N=6$ for each sex, $P<0.05$; Fig. 5).

A homologue of protein disulfide isomerase (PDI, also called thyroid hormone binding protein, THBP; Lee et al.,
1996; Prim and Gilbert, 2001) and adenine nucleotide translocator 2 did not show different expression levels between ovaries and testes of $P$. monodon broodstock $(P$ $>0.05$ ). However, several other transcripts (e.g. $C B X$, phosphatidylinositol 4 kinase, thioredoxin peroxidase and USP9X; $P<0.05$; Table 2) illustrated the preferential expression in ovaries of $P$. monodon.

$C B X$ was preferentially expressed in ovaries than testes of both juvenile $(N=10)$ and broodstock-sized $P$. monodon $(N=$ 12, Fig. 5). Significant different expression levels of ubiquitin specific protease 9, X chromosome homologue (Usp9X, 247 bp, Fig. 6) were observed in broodstock-sized $P$. monodon $(N$ $=13$ and 11 of females and males, $P<0.05)$. Nevertheless, $U s p 9 X$ was only expressed in ovaries but not testes of 4- 


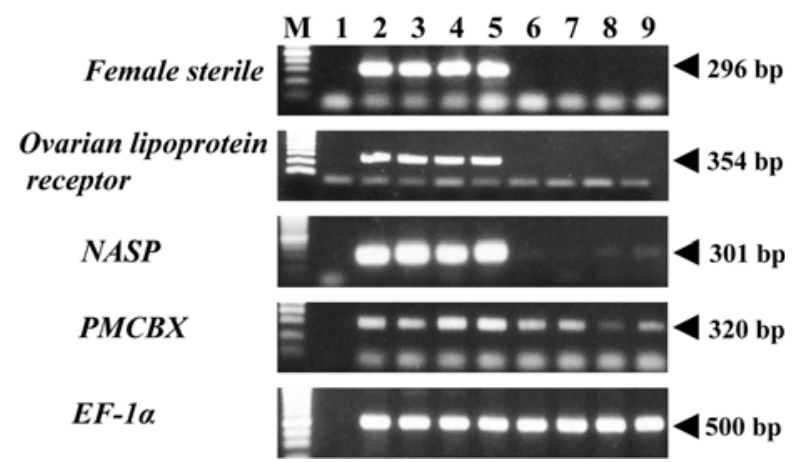

Fig. 5. RT-PCR of a homologue of female sterile, ovarian lipoprotein receptor, NASP and chromobox protein, PMCBX using the first strand cDNA of ovaries (lanes 2-5) and testtes (lanes 6-9) of broodstock-sized P. monodon. EF-1 $\alpha$ was included as the positive control. Lanes 1 are the negative control (without cDNA template).

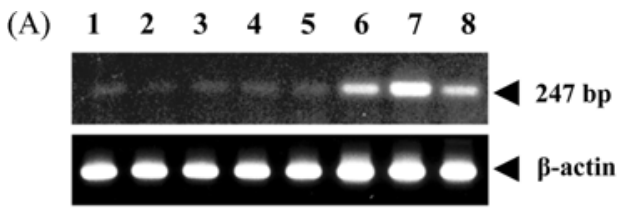

(B)

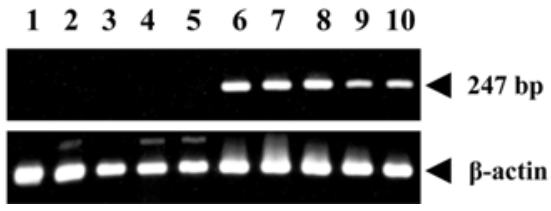

Fig. 6. RT-PCR of a homologue of Usp $9 X$ using the first strand cDNA of testes (lanes 1-5; panels $\mathrm{A}$ and $\mathrm{B}$ ) and ovaries (lanes 6-8; A and lanes 6-10; B) of broodstock-sized (A) and 4-monthold P. monodon (B). Positive control ( $\beta$-actin) was also successfully amplified.

month-old $P$. monodon ( $N=5$ for each sex; Fig. 6).

$U s p 9 X$ is an X-linked orthologue of Fat facets ( $F a f$ in Drosophila and Fam in mice), an ubiquitin-specific protease which is essential for normal development of oocytes in Drosophila. Mutations of Usp $9 X$ lead to abnormal content and the inability of the fertilized eggs to undergo normal embryogenesis. In human, USP9X is one of the possible candidate genes responded for the defects of oocyte proliferation and subsequent gonadal degeneration found in Turner syndrome (Jones et al., 1996). It contributes in the premature ovarian failure syndrome in POF patients (Fassnacht et al., 2006). Moreover, in mice testes, no expression was found in any spermatogenic cells except for weak expression in Sertoli cells. Usp9X expression in embryogenic oocytes was reduced at the newborn stage but its expression reappeared in oocytes at the secondary follicle stage (Noma et al., 2002).

Yamano et al. (2004) illustrated that in most cases ovaries of $M$. japonicus start to develop in the reproductive season but fail to reach full grown requisite for the formation of cortical rods (CRs). Ovaries degenerate without spawning. This is also the major constraint in $P$. monodon. Reduced spawning potential and low degree of maturation of $P$. monodon in captivity crucially prohibits the efficiency of the genetic improvement through domestication and selective breeding programs in this species (B. Withyachumnarnkul, personal communication).

Recently, cyclin $B$, an important regulatory factor in mitosis and meiosis, was recently isolated in $M$. japonicus. Three cyclin $B$ transcripts $(2.4,1.9$ and $1.7 \mathrm{~kb})$ which share an identical ORF of $1203 \mathrm{bp}$ encoding a putative peptide with different length of 3 UTR, coexisted in ovaries. Quantitative realtime RT-PCR revealed that the short transcript $(1.7 \mathrm{~kb})$ was the most abundance, followed by the long $(2.4 \mathrm{~kb})$ and the medium $(1.9 \mathrm{~kb})$, and the three forms of these transcripts displayed different expression profiles during oogenesis (Qiu and Yamano, 2005). Additionally, differential expression of cathepsin $C$ (dipeptidyl peptidase) during the final stages of oocyte maturation of $M$. japonicus was also reported (Qiu et al., 2005). This suggested that various transcripts possess multifunctions and might perform different roles during oogenesis of M. japonicus.

In the present study, a large number of cDNA including sex-related transcripts in ovaries of $P$. monodon were identified. The expression profiles of genes specifically expressed or those preferentially expressed in ovaries (female sterile, ovarian lipoprotein receptor, TSP, NASP, and Usp9X etc.) of $P$. monodon illustrated in the present study implied that these genes may have contributed in ovarian development in $P$. monodon. Molecular mechanisms and expression patterns of genes controlling each step of oocyte maturation and formation of CRs should be further carried out for better understanding the reproductive maturation of $P$. monodon in captivity.

Acknowledgments This research was supported by the National Center for Genetic Engineering and Biotechnology (BIOTEC), Thailand project BT-B-06-SG-09-4603. Student grants are supported by The Golden Jubilee PhD program, The Thailand Research Funds (TRF) for RP and RL and by BIOTEC for KS.

\section{References}

Alekseev, O. M., Widgren, E. E., Richardson, R. T. and O'Rand, M. G. (2005) Association of NASP with HSP90 in mouse spermatogenic cells stimulation of ATPase activity and transport of linker histones into nuclei. J. Biol. Chem. 280, 2904-2911.

Altschul, S. F., Gish, W., Miller, W., Myers, E. W. and Lipman, D. J. (1990) Basic local alignment search tool. J. Mol. Biol. 215, 403-410.

Asian Shrimp Culture Council (1996) Asian Shrimp News $1^{\text {st }}$ quarter.

Avarre, J. -C., Khayat, M., Michelis, R., Nagasawa, H., Tietz, A. 
and Lubzens, E. (2001) Inhibition of de novo synthesis of a jelly layer precursor protein by crustacean hyperglycemic hormone family peptides and posttranscriptional regulation by sinus gland extracts in Penaeus semisulcatus ovaries. Gen. Comp. Endocrinol. 124, 257-268.

Benzie, J. A. H. (1998) Penaeid genetics and biotechnology. Aquaculture 164, 23-47.

Browdy, C. L. (1998) Recent developments in penaeid broodstock and seed production technologies: improving the outlook for superior captive stocks. Aquaculture 164, 3-21.

Clifford, H. C. and Preston, N. P. (2006) Genetic improvement; in Operating Procedures for Shrimp Farming: Global Shrimp OP Survey Results and Recommendations, pp. 73-77. Global Aquaculture Alliance, St. Louis, USA.

Coman, G. J., Arnold, S. J., Peixoto, S., Crocos, P. J., Coman, F. E. and Preston, N. P. (2006) Reproductive performance of reciprocally crossed wild-caught and tank reared Penaeus monodon broodstock. Aquaculture 252, 372-384.

Du, X.-J., Wang, J.-X., Liu, N., Zhao, X.-F., Li, F.-H. and Xiang, J.-H. (2006) Identification and molecular characterization of a peritrophin-like protein from fleshy prawn (Fenneropenaeus chinensis). Mol. Immunol. 43, 1633-1644.

Fassnacht, W., Mempel, A., Strowitzki, T. and Vogt, P. H. (2006) Premature ovarian failure (POF) syndrome: towards the molecular clinical analysis of its genetic complexity. Curr. Med. Chem. 13, 1397-1410.

Felsenstein, J. (1993) PHYLIP (Phylogenetic Inference Package) version 3.5c. Department of Genetics, University of Washington, Seattle.

Gross, P. S., Bartlett, T. C., Browdy, C. L., Chapman, R. W. and Warr, G. W. (2001) Immune gene discovery by expressed sequence tag analysis of hemocytes and hepatopancreas in the Pacific white shrimp, Litopenaeus vannamei, and the Atlantic white shrimp, L. setiferus. Dev. Comp. Immunol. 25, 565-577.

Harrison, K. E. (1990) The role of nutrition in maturation, reproduction and embryonic development of decapod crustaceans: A review. J. Shellfish Res. 9, 1-28.

Huang, X. and Madan, A. (1999) CAP3: A DNA sequence assembly program. Genome Res. 9, 868-877.

Jones, D. O., Mattei, M. G., Horsley, D., Cowell, I. G. and Singh, P. B. (2001) The gene and pseudogenes of $\mathrm{Cbx} 3 / \mathrm{mHP} 1$ gamma. DNA Seq. 12, 147-160.

Jones, M. H., Furlong, R. A., Burkin, H., Chalmers, I. J., Brown, G. M., Khwaja, O. and Affara, N. A. (1996) The Drosophila developmental gene fat facets has a human homologue in $\mathrm{Xp} 11.4$ which escapes X-inactivation and has related sequences on Yq11.2. Hum. Mol. Genet. 5, 1695-1701.

Khayat, M., Babin, P. J., Funkenstein, B., Sammar, M., Nagasawa, H., Tietz, A. and Lubzens, E. (2001) Molecular characterization and high expression during oocyte development of a shrimp ovarian cortical rod protein homologous to insect intestinal peritrophins. Biol. Reprod. 64, 1090-1099.

Klinbunga, S., Penman, D. J., McAndrew, B. J. and Tassanakajon, A. (1999) Mitochondrial DNA diversity in three populations of the giant tiger shrimp, Penaeus monodon. Mar. Biotechnol. 1, 113-121.

Klinbunga, S., Siludjai, D., Wuthijinda, W., Tassanakajon, A., Jarayabhand, A. and Menasveta, P. (2001) Genetic heterogeneity of the giant tiger shrimp (Penaeus monodon) in Thailand revealed by RAPD and mtDNA-RFLP analyses. Mar.
Biotechnol. 3, 428-438.

Khamnamtong, B., Klinbunga, S. and Menasveta, P. (2005) Species identification of five penaeid shrimps using PCR-RFLP and SSCP analyses of $16 \mathrm{~S}$ ribosomal DNA. J. Biochem. Mol. Biol. 38, 491-499.

Leelatanawit, R., Klinbunga, S., Puanglarp, N., Tassanakajon, A., Jarayabhand, P., Hirono, I., Aoki, T. and Menasveta, P. (2004) Isolation and characterization of differentially expressed genes in ovaries and testes of the giant tiger shrimp (Penaeus monodon). Mar. Biotechnol. 6, S506-S510.

Lee, Y.-H., Harada, S., Smith, R. M., Friedman, R. and Jarett, L. (1996). The expression of an insulin binding to cellular thyroid hormone binding protein, but not insulin degrading enzyme, is increased during 3T3-L1 adipocytes differentiation. Biochem. Biophy. Res. Com. 222, 839-843.

Li, F., Xiang, J., Zhang, X., Zhou, L., Zhang, C. and Wu, C. (2003) Gonad development characteristics and sex ratio in triploid Chinese shrimp (Fenneropenaeus chinensis). Mar. Biotechnol. 5, 528-535.

Li, Y., Byrne, K., Miggiano, E., Whan, V., Moore, S., Keys, S., Crocos, P., Preston, N. and Lehnert, S. (2003) Genetic mapping of the kuruma prawn Penaeus japonicus using AFLP markers. Aquaculture 219, 143-156.

Limsuwan, C. (2004) Diseases of Pacific white shrimp (Litopenaeus vannamei) cultured in Thailand. Proceeding of the JSPS-NRCT International Symposium Joint Seminar 2004: Management of Food Safety in Aquaculture and HACCP. pp. 36-41, Kasetsart University, Thailand.

Lyons, R. E. and Li, Y. (2002) Crustacean genomics: implications for the future in aquaculture. AgBiotechNet 4, 1-6.

Makinouchi, S. and Hirata, H. (1995) Studies on maturation and reproduction of pond-reared Penaeus monodon for developing a closed life-cycle culture system. Israeli J. Aqua.-Bamidgeh 47, 68-77.

Meusy, J. -J. and Payen, G. G. (1988) Female reproduction in Malacostracan Crustacea. Zool. Sci. 5, 217-265.

Noma, T., Kanai, Y., Kanai-Azuma, M., Ishii, M., Fujisawa, M., Kurohmaru, M., Kawakami, H., Wood, S. A. and Hayashi, Y. (2002) Stage- and sex-dependent expressions of Usp9x, an Xlinked mouse ortholog of Drosophila Fat facets, during gonadal development and oogenesis in mice. Mech. Dev. 119S, S91S95.

Okumura, T. (2004) Perspectives on hormonal manipulation of shrimp reproduction. JARQ 38, 49-54.

Okumura, T., Kim, Y. K., Kawazoe, I., Yamano, K., Tsutsui, N. and Aida, K. (2006) Expression of vitellogenin and cortical rod proteins during induced ovarian development by eyestalk ablation in the kuruma prawn, Marsupenaeus japonicus. Comp. Biochem. Physiol. A 143, 246-253.

Perrimon, N., Mohler, D., Engstrom, L. and Mahowald, A. P. (1986) $X$-linked female-sterile loci in Drosophila melanogaster. Genetics 113, 695-712.

Pertea, G., Huang, X., Liang, F., Antonescu, V., Sultana, R., Karamycheva, S., Lee, Y., White, J., Cheung, F., Parvizi, B., Tsai, J. and Quackenbush, J. (2003) TIGR gene indices clustering tools (TGICL): a software system for fast clustering of large EST datasets. Bioinformatics 19, 651-652.

Preston, N. P., Sellars, M. J. and Coman, F. E. (2004) Ploidy manipulation induces sterility in Kuruma Prawns. Global Aquaculture Advocate 7, 70-71. 
Primm, T. P. and Gilbert, H. F. (2001) Hormone binding by protein disulfide isomerase, a high capacity hormone reservoir of the endoplasmic reticulum. J. Biol. Chem. 276, 281-286.

Qiu, G. -F. and Yamano, K. (2005) Three forms of cyclin B transcripts in the ovary of the kuruma prawn Marsupenaeus japonicus: Their molecular characterizations and expression profiles during oogenesis. Comp. Biochem. Physiol. B 141, 186-195.

Qiu, G. -F., Yamano, K. and Unuma, T. (2005) Cathepsin C transcripts are differentially expressed in the final stages of oocyte maturation in kuruma prawn Marsupenaeus japonicus. Comp. Biochem. Physiol. B 140, 171-181.

Quackenbush, L. S. (2001) Yolk synthesis in the marine shrimp, Penaeus vannamei. Am. Zool. 41, 458-464.

Richardson, R. T., Batova, I. N., Widgren, E. E., Zheng, L.-X., Whitfield, M., Marzluff, W. F. and O'Rand, M. G. (2000) Characterization of the histone H1-binding protein, NASP, as a cell cycle-regulated somatic protein. J. Biol. Chem. 275, 3037830386.

Rojtinnakorn, J., Hirono, I., Itami, T., Takahashi, Y. and Aoki, T. (2002) Gene expression in haemocytes of kuruma prawn, Penaeus japonicus, in response to infection with WSSV by EST approach. Fish Shellfish Immunol. 13, 69-83.

Rosenberry, B. (2003) World shrimp farming 2003. Shrimp News International, San Diego, USA.

Saitou, N. and Nei, M. (1987) The neighbor-joining method: a new method for reconstructing phylogenetic trees. Mol. Biol. Evol. 4, 406-425.

Sambrook, J. and Russell, D. W. (2001) Molecular Cloning: A Laboratory Manual, $3^{\text {rd }}$ ed., Cold Spring Harbor Laboratory Press, New York, USA.

Shen, Y. Q., Xiang, J. H., Wang, B., Li, F. H. and Tong, W. (2004) Discovery of immune related factors in Fenneropenaeus chinensis by annotation of ESTs. Prog. Nat. Sci. 14, 47-54.

Srisuparbh, D., Klinbunga, S., Wongsiri, S. and Sittipraneed, S. (2003) Isolation and characterization of major royal jelly cDNAs and proteins of the honey bee (Apis cerana). J. Biochem. Mol. Biol. 36, 572-579.

Supungul, P., Klinbunga, S., Pichyangkura, R., Hirono, I., Aoki, T. and Tassanakajon, A. (2004) Antimicrobial peptides discovered in the black tiger shrimp Penaeus monodon by using the EST approach. Dis. Aquat. Org. 61, 123-135.

Thompson, J. D., Higgins, D. G. and Gibson, T. J. (1994) Clustal $\mathrm{W}$ : improving the sensitivity of progressive multiple sequence alignment through sequence weighting, position-specific gap penalties and weight metrix choice. Nucleic Acids Res. 22, 4673-4680.

Welch, J. E. and O'Rand, M. G. (1990) Characterization of a sperm-specific nuclear autoantigenic protein. II. Expression and localization in the testis. Biol. Reprod. 43, 569-578.

Withyachumnarnkul, B., Boonsaeng, V., Flegel, T. W., Panyim, S. and Wongteerasupaya C. (1998) Domestication and selective breeding of Penaeus monodon in Thailand, in: Proceedings to the Special Session on Advances in Shrimp Biotechnology, Felgel, T. (ed.), pp. 73-77, The Fifth Asian Fisheries Forum: International Conference on Fisheries and Food Security Beyond the Year 2000. 11-14 November 1998. Chiengmai, Thailand.

Yamano, K., Qiu, G.F. and Unuma, T. (2004) Molecular cloning and ovarian expression profiles of thrombospondin, a major component of cortical rods in mature oocytes of penaeid shrimp, Marsupenaeus japonicus. Biol. Reprod. 70, 1670-1678.

Yamaguchi, K., Hidema, S. and Mizuno, S. (1998) Chicken chromobox proteins: cDNA cloning of CHCB1, $-2,-3$ and their relation to $W$-heterochromatin. Exp. Cell Res. 242, 303314. 